\title{
A quantitative comparison of intranasal and intratracheal administration of coarse PM in the mouse
}

\author{
Angela Lee Linderholm¹ ${ }^{1}$ Lisa M. Franzi ${ }^{1}$, Keith J. Bein ${ }^{2,3}$, Kent E Pinkerton ${ }^{2}$ and Jerold A. Last ${ }^{1 *}$ \\ ${ }^{1}$ Department of Pulmonary and Critical Care Medicine, University of California, Davis, CA 95616, USA \\ ${ }^{2}$ Center for Health and the Environment, University of California, Davis, CA 95616, USA \\ ${ }^{3}$ Air Quality Research Center, University of California, Davis, CA 95616, USA
}

\begin{abstract}
Acute lung inflammation induced by exposure to coarse particulate matter (PM) was evaluated by assay of inflammatory cells in whole lung lavage from mice administered the same nominal dose of PM by either the intratracheal (IT) or intranasal (IN) route. Based on higher total cells recovered and shifts to a higher recovery of neutrophils in the lavage fluid, the IT route was at least three times more effective in delivery of $\mathrm{PM}_{10-2.5}$ to the lung than the IN route. These differences in the route of particle administration are likely to reflect the filtering efficiency of the nasal cavity to block deep lung penetration of larger particles to the lower respiratory tract. The results are compared with the predictions from models of the deposition of dry PM of comparable size after inhalation and with previously reported comparisons of IT and IN delivery of solutions or suspensions containing soluble drugs or insoluble particles. In addition, the variance in the observed data was substantially lower in mice administered PM by the IT route as compared to IN aspiration. We would suggest that especially in situations where the amount of PM is limited, the IT route has several advantages over IN administration.
\end{abstract}

\begin{abstract}
Abbreviations: IT: Intratracheal; IN: Intranasal; MMAD: Mass Median Aerodynamic Diameter; PBS: Phosphate-buffered Saline; PM: Particulate Matter
\end{abstract}

\section{Introduction}

Epidemiological studies have demonstrated reproducible associations between PM concentrations measured in ambient air and increased morbidity and mortality in exposed populations [1]. Current air pollution control policies in the USA (http://epa.gov/ttn/naaqs/ standards/pm/s_pm_history.html) and in California (http://www. arb.ca.gov/research/aaqs/pm/pm.htm) regulate PM levels in ambient air by size (coarse, fine) and mass (in each size range). PM in the size range that can be inhaled into the lungs by humans is classified for regulatory purposes according to the size of the particles: coarse PM with mass median aerodynamic diameter (MMAD) between 2.5 and $10 \mu \mathrm{m}\left(\mathrm{PM}_{10-2.5}\right)$ and fine PM with MMAD less than $2.5 \mu \mathrm{m}\left(\mathrm{PM}_{2.5}\right)$. Studies in whole animals [2] and in cultured cells [3,4] have attempted to elucidate underlying mechanisms of action of the various PM components with size-fractionated samples collected from ambient air from various locations worldwide [5]. Our long-term goal is to understand the toxicity of agricultural dusts, generated in the hot and dry Central Valley of California, to agricultural workers in the fields. To accomplish this goal we will expose laboratory mice to the coarse $\mathrm{PM}$ fraction isolated from ambient air from test sites in California's San Joaquin Valley (SJV). These specific sources of PM are being studied by several research groups at UC Davis, and will undergo rigorous chemical and toxicological characterization. However, some very basic questions with regard to study design arose early in our planning process and seemed worthy of beginning with additional experiments to optimize our collaborative approach.

Researchers who study the toxicity of different particle preparations have several choices of methods available to deliver PM directly to the lung, rather than administering the particles to the lung systemically via the vascular system. The available alternatives for direct delivery of PM to the lungs for animal studies include whole-body inhalation in exposure chambers, nose-only inhalation in a specially designed apparatus, intratracheal (IT) injection directly into the lungs, or via intranasal (IN) aspiration. The pros and cons of each of these routes of administration have been discussed in detail elsewhere [6,7]. It is worth noting that because of the efficiency of the absorption mechanisms of the rodent nose and the fact that rats and mice are obligate nose breathers, the only means of administration that delivers the entire administered dose to the lungs is IT instillation [6]. With severely limited amounts of size-fractionated PM available and concerns about ingestion of PM trapped on and in the fur of cage mates, whole-body inhalation is generally not a viable option for these types of experiments. Noseonly exposure requires less material than whole body exposure, but introduces experimental variables like additional stress to the animals and increased animal handling that can affect the experimental outcome in difficult to predict ways. Thus, intranasal aspiration, which is simpler to perform and felt to be a more toxicologically relevant route of PM administration than direct intratracheal dosing, is becoming a popular choice for these types of experiments [8]. In addition, IT instillation

Correspondence to: Jerold A. Last, Department of Pulmonary and Critical Care Medicine, CCRBM, 6519 GBSF, 451 Health Sciences Drive, University of California, Davis, CA 95616, USA, Tel: 1530752-6230; Fax: 1530752-8632, E-mail: jalast@ucdavis.edu

Key words: air pollution, lung inflammation, $P M_{10-2.5}$ inhalation toxicology, methodology

Received: November 22, 2014; Accepted: January 25, 2015; Published: January 29,2015 
of very high doses of PM can cause particle overload to the lungs, with concomitant false positive results with regard to PM toxicity [9]. Thus, IT instillation as a "physiological route" of administration may be viewed with some concern by advocates of the IN route. However, Driscoll et al. [10] have demonstrated the equivalence of the IT route with inhalation if care is taken to use appropriate low doses (in the submg range) in the IT experiments.

Our primary objective in the current study was to directly compare the acute responses in the lungs of mice exposed to the coarse PM fraction collected from ambient air at our test site located in a rural area southeast of the city of Fresno when the same quantity of the PM was administered by either IN aspiration or by IT injection. We hypothesized that similar results would be obtained qualitatively by both routes of exposure, but that larger effects would be observed at a given dose by the IT route, due to removal of PM from the administered dose by the nose and nasopharynx during IN aspiration. We predicted that the efficiency of removal by the nose and nasopharynx would be on the order of $50 \%$ of the total administered dose [9], in contrast to administering the same total dose directly into the lung by IT injection. This estimate is based on earlier studies of lung deposition of dry PM or aerosols inhaled by laboratory animals $[9,11]$. We are not aware of any such rigorous studies of PM deposition by the IN or IT route, perhaps because investigators assume that particle deposition will vary with the exact technique used. The delivery technique may have significant effects on the pattern, extent, and timing of lung toxicity and subsequent remodelling [7]. Intratracheal techniques include (1) instillation, which involves injecting particles suspended in saline through a catheter inserted into the trachea of the animal; (2) aspiration, which entails administrating a suspension as droplets in a puff of air; and (3) intratracheal inhalation, which involves cannulating the trachea, attaching the open end of the cannula to a port of an aerosolization system and ventilating the animal at a known rate and pressure [12-14]. An additional goal of our experiments was to test whether the older models of PM deposition based upon the inhalation route of delivery would accurately predict lung delivery via the IN and IT routes in our experiments in the present study.

Another goal of the current study was to estimate how much of the lung inflammatory activity observed with this coarse PM preparation could be ascribed to its content of endotoxin, a frequently encountered contaminant of coarse PM due to the similarity in size between gramnegative bacteria and the size of particles in this particular fraction of $\mathrm{PM}$ in the ambient air. $\mathrm{PM}_{10}$ is also sufficiently large to serve as a carrier of endotoxin on its surface. Endotoxin, part of the outer membrane of Gram-negative bacteria, is known to cause airway inflammation and has been suggested by several groups to be a causative agent in PMmediated lung injury [15-18] and is concentrated in the coarse PM fraction $[19,20]$.

\section{Materials and methods}

\section{PM preparation}

The coarse PM used in this study was collected at a field site located on the grounds of the University of California Kearney Research and Extension Center in Parlier, California. $\mathrm{PM}_{2.5}$ high-volume sampler systems (Tisch Environmental Inc., TE-6070V-2.5-HVS) equipped with $\mathrm{PM}_{10}$ size selective heads (Tisch Environmental Inc., TE-6001), operating at a flow rate of 40 cubic feet per minute, were loaded with aluminum foil substrates for collecting the coarse $\mathrm{PM}$ fraction $\left(\mathrm{PM}_{10-2.5}\right.$ $=2.5<\mathrm{Dp} 50<10 \mu \mathrm{m})$ and Teflon coated borosilicate glass microfiber filters (Pall Corporation, TX40H120WW-8X10) for collecting the fine
PM fraction $\left(\mathrm{PM}_{2.5}=\mathrm{Dp} 50<2.5 \mu \mathrm{m}\right)$. Aluminum foil substrates were prebaked at $500^{\circ} \mathrm{C}$ for 24 hours and glass microfiber filters were precleaned via successive sonication in milli- $\mathrm{Q}$ water, dichloromethane, and hexane. Field blanks were included for all studies. Only the coarse PM fraction was used in this study. The PM was scraped from the aluminum substrates using a metal spatula. Previous studies have been reported with samples collected using the same high-volume sampler systems [21].

\section{Animals}

Specific pathogen-free female BALB/c mice, 8 weeks old (nominal $20 \mathrm{~g}$ ), were purchased from Jackson Laboratories (West Sacramento, CA). Animals were housed, 4 animals per cage, in filtered Bio-Clean facilities in the AALAC-approved Animal Resources Center (UC Davis, CA). Mice received water and standard feed (Purina Rat Chow) ad lib and were allowed to acclimate for a week prior to any experimental procedures. The animals were kept on a 12-h light/dark cycle at room temperature $\left(20-25^{\circ} \mathrm{C}\right)$ and $30-70 \%$ relative humidity. All procedures were performed under an Institutional Animal Care and Use Committee-approved protocol.

\section{IT administration of PM}

Our procedures for IT instillation have been described in detail previously [22]. Prior to instillation, mice were lightly anesthetized with isoflurane via inhalation in an enclosed box chamber. Instillations ( $50 \mu \mathrm{g}$ of PM suspended in $50 \mu \mathrm{L}$ of phosphate-buffered saline) were performed directly into the trachea using a glass syringe equipped with a blunt-tipped 22-gauge needle. Immediately prior to instillation, PM preparations were vortex mixed for $30 \mathrm{~s}$ to suspend the material. After instillation, the mouse was allowed to recover under visual control before placement back into the cage for 24 hours after exposure.

\section{IN administration of PM}

Particles were suspended in phosphate buffered saline (PBS), $1 \mathrm{mg} /$ $\mathrm{mL}$, and vortex mixed immediately before aspiration. Mice were lightly anesthetized with isoflurane and monitored for depth of anesthesia. Once anesthetized, mice were place in the supine position and $25 \mu \mathrm{L}$ of suspended PM were instilled with a micropipetor dropwise into each naris. After aspiration of the fluid, the mice were allowed to recover under visual observation before placement back into the cage for 24 hours after exposure.

\section{Bronchoalveolar lavage}

Our procedures have been described in detail previously [22] Briefly, mice were euthanized with an overdose of pentobarbital/ dilantin via intraperitoneal injection. The tracheas were cannulated and the lungs were lavaged two times each with $1 \mathrm{~mL}$ instillations (2 $\mathrm{mL}$ total) of phosphate buffered saline (PBS), pH 7.6 (Mediatech, Inc, Herndon, VA). The total lavage fluid from each mouse lung was combined and centrifuged at $2000 \mathrm{rpm}$ for $10 \mathrm{~min}$ using a bench top unit (Centrifuge \#5415C, Eppendorf, New York, NY). The supernatant was removed and the resulting pellet was suspended in ACK Lysis Buffer (0.15 M NH 4 Cl, $1.0 \mathrm{M} \mathrm{KHCO}_{3}, 0.1 \mathrm{mM} \mathrm{Na}_{2}$ EDTA, $\left.\mathrm{H}_{2} \mathrm{O}\right)$ and centrifuged for another $10 \mathrm{~min}$. The supernatant was discarded and the pellet was suspended in $1 \mathrm{~mL}$ of PBS. The trypan blue exclusion method [23] was used to count the total number of viable cells in each BAL sample using a hemocytometer. Additional cell cytospin preparations were performed with $100 \mu \mathrm{L}$ of BAL fluid using a cytocentrifuge, (StatSpin Cytofuge 2, Iris, Westwood, MA). Prepared cytospinslides were stained with DiffQuick $^{\circledR}$ (International Reagent Corp, Kobe, Japan). 


\section{Statistical analysis of data}

Prism 4.0 (GraphPad Software, San Diego, CA) was used forthe analysis of data. All values are expressed as mean values \pm SEM (standard error) unless otherwise noted. Parametric analysis of data was conducted using Student's t-test. For experiments using more than two groups, data were analyzed by ANOVA followed by post testing with Tukey's honestly significant difference test. Differences were considered significant if the $\mathrm{p}$ value was $<0.05$.

\section{Results}

Our first question was a simple one: What is the most efficient method to deliver PM directly to the lungs of experimental animals? More specifically, if we directly compare the effects of administration of the same dose of PM by the IT and IN routes, do we see the same effects qualitatively and quantitatively? If not, which of these methods is the better choice for experimental work comparing different batches or types of particles, especially under conditions where the amount of PM available for these experiments may be severely limited? In preliminary experiments we used different batches of agricultural dusts to demonstrate dose-response behavior of mouse lungs upon exposure to various concentrations of rural agricultural-derived PM. For example, we previously reported a linear dose-response between 0 and $50 \mu \mathrm{g}$ of PM when we quantified total cells in the lung lavage fluid from mice instilled with PM via the IT route [22]. In additional experiments where we attempted to extend the dose-response curve to $75-100 \mu \mathrm{g}$, the observed responses were inconsistent and highly variable, and the results did not demonstrate continued linearity of the dose-response curve (data not shown). The $50 \mu \mathrm{g}$ dose of PM isolated from ambient air and administered via IT instillation is the highest dose we have tested thus far that we can conclude with confidence gives us results consistently in the linear range of the dose-response curve. Thus, in our following experiments, we elected to compare the effect on the lung inflammation when $50 \mu \mathrm{g}$ of coarse PM was delivered to the lungs of mice by either the intratracheal or intranasal route. To do this, we exposed mice via either IT injection or IN aspiration. We then determined the total number of cells recovered from the mice by bronchoalveolar lavage 24 hours after PM administration. The results are shown in Figure 1. When we compare groups of mice instilled with PBS (controls), the ratio of cells recovered after PBS treatment

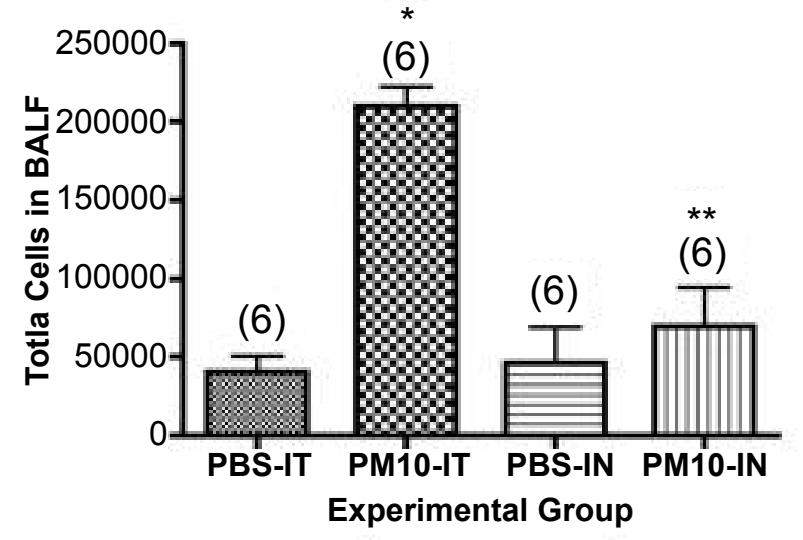

Figure 1. Total cells obtained by lung lavage from mice administered PM either IT or IN. Data are mean values \pm SEM. The number of animals in each group is indicated in parenthesis. *, $\mathrm{P}<0.001$ compared with the PBS-IT group; **, $\mathrm{P}<0.001$ compared with the $\mathrm{PM}_{10}$-IT group.

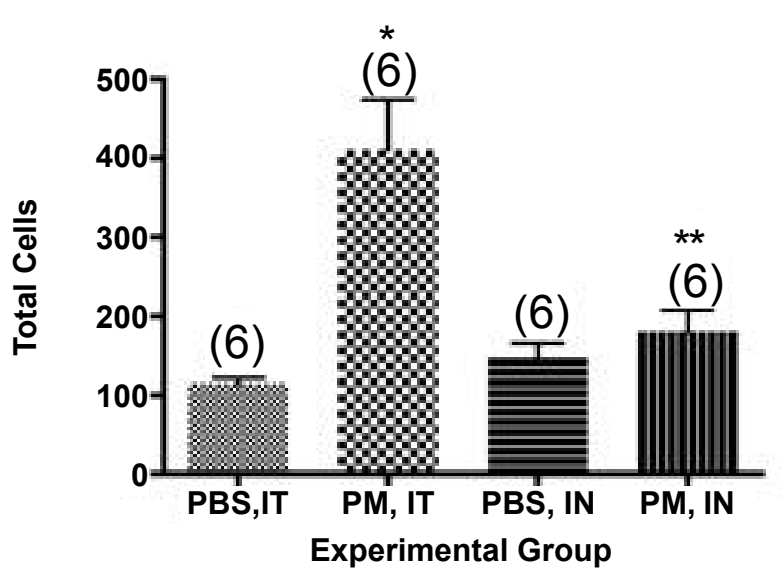

Figure 2. Total cells counted in the cytocentrifuge preparations from mice administered PM.

was 0.88 (IT/IN). The comparable ratio for the two groups after PM instillation was 3.0 (IT/IN). The difference in total cells recovered after PM administration via instillation between the two routes was highly significant $(\mathrm{P}<0.001)$, whereas the difference in total cells recovered after PBS administration was not significant $(\mathrm{P}>0.05)$.

Normal mouse lungs (filtered air controls or PBS instilled) contain about 40,000-50,000 pulmonary alveolar macrophages when they are lavaged using these procedures. Thus, the actual increase in total cell number in the lungs of the animals administered PM by the two different routes is considerably larger than the values suggested by the simple comparison above. If we assume the "background" cells before PM administration was the same value as we observed in the PBS controls for each group and subtract this value from the total cells in the PM instilled group, we can calculate the "real" net increase in total cells after PM administration for each group as follows. IT PM control $(209,722-40,278)=169,444$; IN PM - control $(69,445-45,834)$ $=23,611$. The ratio for the two groups after PM instillation was 7.2-fold (IT/IN) (difference $=145,833$ net total cells in the lavage). To further examine the basis for the difference we observed between IT and IN administration of our PM preparation, and to verify our assumptions about baseline values for macrophage content in the lung lavages of control mice, we examined the cell differentials in the lavage fluid from both groups of mice. IT instillation of PM isolated from ambient air into mice is usually associated with an acute neutrophilic influx that peaks at about 24 hours after PM administration [22]. We hypothesized that IT versus IN instillation would give the same results qualitatively, but the number of neutrophils (PMNs) recovered in the BALF would differ by the same ratio as the total cells recovered. As shown in Figure 2 , in the cytocentrifuge fields evaluated we recovered a total of $411 \pm 63$ total cells after IT instillation versus $181 \pm 28$ after IN administration, a ratio of 2.3 in the cytocentrifuge preparation counted. If we correct for the "background" of total cells in the PBS instilled mice, as above, we find a ratio of $(411-115) /(181-147)=296 / 34=8.7$-fold . Considering all of the uncertainties in this calculation, these values are in good agreement with the results calculated from the total cell counts shown in Figure 1.

Of the total cells counted in the cytocentrifuge preparation, $54 \pm 8 \%$ are neutrophils in the IT instilled mice, while $24 \pm 10 \%$ are PMNs in the animals administered PM by the IN route (Figure 3 ). These values are significantly different $(\mathrm{P}<0.05)$. Inspection of the error bars in Figures 


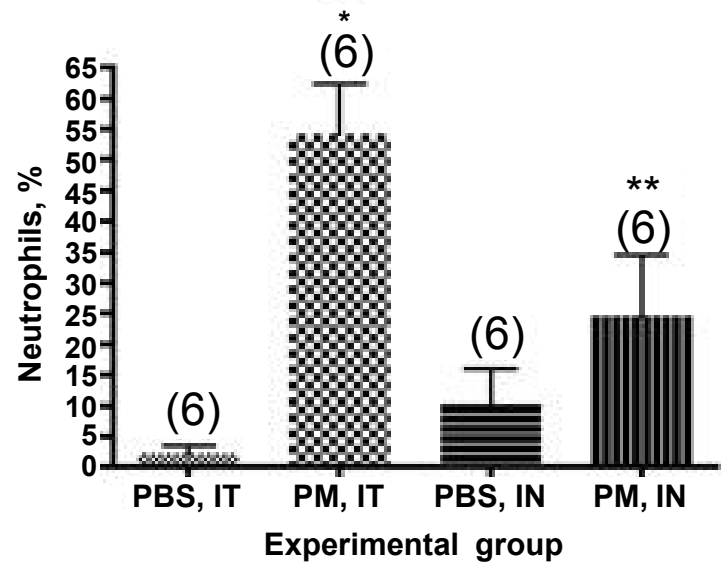

Figure 3. Percentage of neutrophils (PMNs) counted in the cytocentrifuge preparations from mice administered PM. *, $\mathrm{P}<0.001$ compared with the PBS-IT group; **, $\mathrm{P}<0.05$ compared with the PM10-IT group.

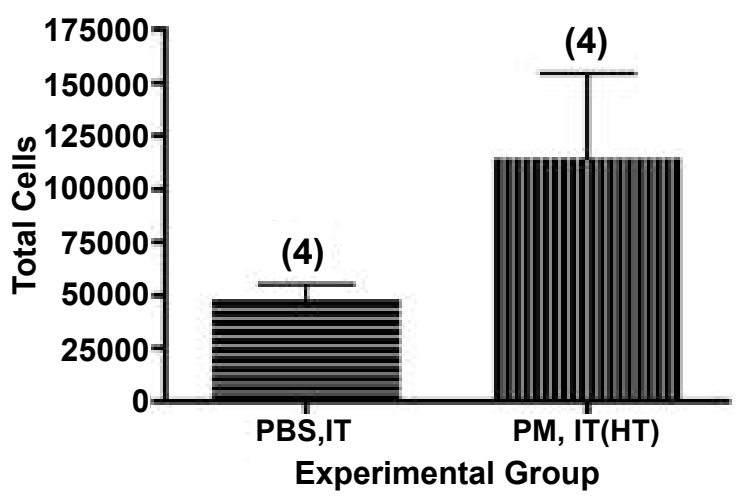

Figure 4. Total cells obtained by lung lavage from mice administered heat-treated PM by the IT route.

1 and 3 (data expressed as means and SEM in these figures) suggests that the coefficient of variation is lower in the IT instilled animals than the animals that aspirated the PM by the IN route. This assumption is consistent with the observation that some of the animals presented the PM for IN aspiration showed signs of variable interception of the PM by the nose: foaming and/or sneezing. To test this assumption we calculated the coefficient of variation $(\mathrm{CV}$, the ratio of the $\mathrm{SD}$ to the mean values for the groups) for the different routes of administration. For total cells, the IT value was $15 \%$ versus $89 \%$ for the IN value. For the $\%$ neutrophils, the IT value was $15 \%$ versus $42 \%$ for the IN value. Thus, the IT route seems to result in more consistent results among treated mice than the IN route.

In previous work from our laboratory we have examined the relative contribution to inflammation of volatile and organic constituents of the coarse PM by comparing the activity of the IT instilled PM with heat-treated $\mathrm{PM}\left(24\right.$ hours at $\left.130^{\circ} \mathrm{C}\right)$. A comparable experiment was performed with the PM fraction used in the current studies.

We found a reduction of $45 \%$, from $209,722 \pm 40,278$ to $114,584 \pm$ 39,875 , total cells in the BALF, as shown in Figure 4 and 1 . This value may be compared with our previously reported result of a $59 \%$ loss of total cells in the BALF using this technique with a sample of endotoxin- rich PM collected from the ambient air near a working dairy barn on the UC Davis campus [24]. In the current experiment, $36 \pm 9 \%$ of the lavaged cells in the mice instilled with the heat-treated PM were neutrophils, as shown in Figure 5, consistent with the innate immune response we might expect from LPS in the particle preparation.

\section{Discussion and conclusions}

Wang et al. [25] compared the biodistribution and selected pharmacokinetic parameters for the water-soluble drug rizatriptan administered IT or IN to rats. Among their findings was a ratio of the maximum concentration of the drug in plasma by the two different routes of $>1360$ versus $422 \mathrm{ng} / \mathrm{mL}$, a ratio of $>3.2: 1$. Lacher et al. [26] compared the efficiency of administration of quartz dust (Min-U-Sil-5, 1.5-2.0 $\mu \mathrm{m}$ MMAD at a concentration of $1 \mathrm{mg} / 25 \mu \mathrm{L}$ ) into mice by the IT and IN routes. Recovery of total cells in the BALF three days later was about 600,000 versus 300,000 (a ratio of 2:1), respectively. About $50 \%$ of the total cells recovered in the BALF were neutrophils after either route of administration. These authors also measured the protein content of the lavage fluid, an index of lung damage. The ratio of protein content $(\mathrm{mg} / \mathrm{mL})$ found in the BALF after IT or IN administration in the same experiments was about 1500: $300=5: 1$. While experimental procedures varied widely between these experiments and ours, it is noteworthy that all of these experiments consistently find, based on biomarkers of response, IT instillation seems to deliver a much higher fraction of the administered dose of PM to the lung than does IN aspiration. In the examples cited, this ratio is $>3.2: 1$ and $5: 1$, which may be compared with our results in the present study where we find a ratio of 3:1 (Figure 1) for total cells recovered in the lavage fluid when we compare the IT with the IN route of administration. This value is also remarkably consistent with the calculated values for nasopharyngeal deposition of inhaled PM in the mouse breathing particles of $2.5-10 \mu \mathrm{m}$ in diameter $[9,11]$, which is a range from about $50-75 \%$ of the inhaled dose, with the larger particles (which contain most of the mass) being more effectively removed in the nose. Thus, our results are entirely consistent with the IT route being more efficient than IN due entirely to bypassing the nasopharyngeal defense mechanisms of the mouse by direct administration to the trachea. In addition, the IT route gave us a smaller coefficient of variation in the data than we found with IN administration in these experiments. If all of the difference between IT and IN administration is accounted for by differences in the amount of the administered dose directly delivered into the lung, we can

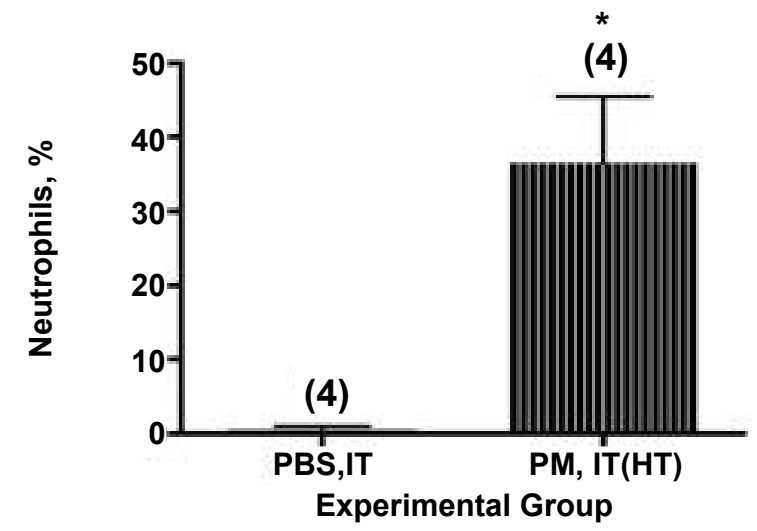

Figure 5. Percentage of neutrophils (PMNs) counted in the cytocentrifuge preparations from mice administered heat-treated PM by the IT route. *, $\mathrm{P}=0.007$ (Student's t-test, twotailed) compared with the PBS-IT group. 
calculate that only about $33 \%$ of the $\mathrm{PM}_{10-2.5}$ dose presented to mice for IN aspiration actually gets to the lung. The remainder is either being removed during passage through the nasopharyngeal region or by sneezing and other maneuvers by the animal to clear the nose of foreign liquids being introduced. Thus, we can answer our first question: What is the most efficient (and consistent) method to deliver PM directly to the lungs of experimental animals? The IT route is at least three times more efficient than the IN route in delivering an administered dose of an agent dissolved or dispersed in an aqueous solution.

The pro-inflammatory activity of coarse $\mathrm{PM}\left(\mathrm{PM}_{10}\right.$ or $\left.\mathrm{PM}_{10-2.5}\right)$ collected from ambient air in Mexico City acting on cultured mouse monocytes has been ascribed in part or entirely to its content of endotoxin [27]. These results are consistent with similar findings with $\mathrm{PM}_{10-2.5}$ collected from ambient air in Germany instilled intratracheally into the lungs of mice [28]. Endotoxin appears to be a ubiquitous component of coarse PM collected from ambient urban air in the Eastern United States and from Western Europe. However, this could be an artifact of PM sample collection rather than an accurate indicator of what people are actually inhaling. We have suggested elsewhere [22] that endotoxin contamination of collection substrates might occur with samples of coarse PM collected from ambient air when the relative humidity is high (which would favor bacterial contamination and bacterial growth on nutrient-rich PM), but may not be a significant factor with PM samples collected in ambient air from the arid climates of many of the Western United States. In our previous studies of the pro-inflammatory activity of PM collected from ambient air in California's Central Valley under hot and dry summer conditions, we found essentially no endotoxin in the PM (coarse or fine) preparations [22]. On the other hand, we found up to $80 \%$ of the pro-inflammatory activity in coarse PM collected under the same hot and dry conditions from just outside of a working dairy barn as due to endotoxin [24]. The present batch of coarse PM we used in this study seems to have an organic chemical content, presumably including endotoxin, intermediate between these two values. The heat-labile material we measured in these experiments could be a component of the PM as it actually occurs in the ambient air, or endotoxin from contaminating bacteria could have been introduced into the coarse PM fraction on the substrate after collection or during handling and storage.

Regulatory agencies in the USA and worldwide currently seem to be focused more on regulation of $\mathrm{PM}_{2.5}$ ("fine $\mathrm{PM}^{\text {") }}$ than of $\mathrm{PM}_{10-2.5}$ ("coarse PM") concentrations in ambient air for protection of the public from adverse health effects of exposure to air pollution. However, animal studies consistently show acute toxicity of PM of both size classes at similar concentrations in animals exposed by inhalation, insufflation, or instillation. Thus, characterization of various methods of delivery with respect to all of the different size classes of PM remains a necessity for the analysis of comparative toxicity of different size fractions and different sources of particles isolated from ambient air. And, quite clearly, different sources of $\mathrm{PM}_{10-2.5}$ have different toxicity at equivalent doses, presumably related to the chemistry of their specific components [29].

The lung lavage conditions applied in these studies, which extract most but not all cells from the airspaces, yield moderate amounts of cells. This number is sufficiently sensitive to show acute increases in cell numbers and significant changes in cell differentials. Both methods of PM administration elicit the influx of neutrophils into the lungs, but to a much greater degree by IT compared with IN. These findings suggest that both the dose delivered to the lungs and the presence of coarse PM can drive both macrophage- and neutrophil-induced inflammation.
Such studies further confirm the importance of better understanding the mechanisms of coarse PM toxicity throughout the respiratory tract. These results also suggest that the toxicity of coarse PM in ambient air may be of significant concern for human health, as is currently the case with fine PM and ultrafine particles.

In summary, the mouse is an important animal model for testing the biological activity of coarse PM in the respiratory tract. The two methods applied in this study, IN and IT administration, dramatically indicate the potential of the nasal cavity to serve as a highly efficient filter for what enters the lung, even when using instillation methods rather than inhalation. This study further confirms the potent, acute effects of coarse PM within the lungs. The total dose delivered directly to the lungs by IT instillation ( $50 \mu \mathrm{g} /$ mouse) in this study represents a moderate dose that could reflect true environmental conditions when compared with particle inhalation into the human lung from ambient air. In our animal model we see a strong reaction with a dramatic influx of total inflammatory cells that is driven by both macrophages and neutrophils. In contrast, delivery by intranasal instillation of an equivalent dose demonstrates the protective, and highly effective, filtering nature of the nasal cavity to minimize the entry of coarse PM into the deep lung. Authorship and Contributions: ALL and LMF performed the experiments, KJB collected the PM samples from ambient air used for the studies, JAL, KEP, LMF, and KJB designed the study, all of the authors contributed to writing the manuscript and approved the final version for submission.

\section{Acknowledgements}

The research reported herein was supported, in part, by a grant from The National Institute of Occupational Safety and Health (NIOSH), 2 U54 OH007550.

\section{References}

1. Dockery DW (2009) Health effects of particulate air pollution. Ann Epidemiol 19: 257-263. [Crossref]

2. Gilmour MI, McGee J, Duvall RM, Dailey L, Daniels M, et al. (2007) Comparative toxicity of size-fractionated airborne particulate matter obtained from different cities in the United States. Inhal Toxicol 19 Suppl 1: 7-16. [Crossref]

3. Ntziachristos L, Froines JR, Cho AK, Sioutas C (2007) Relationship between redox activity and chemical speciation of size-fractionated particulate matter. Part Fibre Toxicol 4: 5. [Crossref]

4. Ayres JG, Borm P, Cassee FR, Castranova V, Donaldson K, et al. (2008) Evaluating the toxicity of airborne particulate matter and nanoparticles by measuring oxidative stress potential--a workshop report and consensus statement. Inhal Toxicol 20: 75-99. [Crossref]

5. Happo MS, Hirvonen MR, Halinen AI, Jalava PI, Pennanen AS, et al. (2008) Chemical compositions responsible for inflammation and tissue damage in the mouse lung by coarse and fine particulate samples from contrasting air pollution in Europe. Inhal Toxicol 20: 1215-1231. [Crossref]

6. Witschi H, Pinkerton KE, van Winkle LS, Last JA (2007) Toxic responses of the respiratory system in: Casarett and Doull's Toxicology: The Basic Science of Poisons, (7th Edn.), Klassen, (Eds.), McGraw-Hill Medical Publishing Division, New York. 609-630.

7. Madl AK, Kadir T, Pinkerton KE (2015) Particle Toxicities. Comprehensive Toxicology, Elsevier, New York, in press.

8. Steerenberg PA, Withagen CE, van Dalen WJ, Dormans JA, Cassee FR, et al. (2004) Adjuvant activity of ambient particulate matter of different sites, sizes, and seasons in a respiratory allergy mouse model. Toxicol Appl Pharmacol 200: 186-200. [Crossref]

9. Oberdörster G, Sharp Z, Atudorei V, Elder A, Gelein R, et al. (2004) Translocation of inhaled ultrafine particles to the brain. Inhal Toxicol 16: 437-445. [Crossref]

10. Driscoll KE, Costa DL, Hatch G, Henderson R, Oberdorster G, et al. (2000) Intratracheal instillation as an exposure technique for the evaluation of respiratory tract toxicity: uses and limitations. Toxicol Sci 55: 24-35. [Crossref] 
11. H. Smith (1994) International Commission on Radiological Protection. Annals of the ICRP: Human Respiratory Tract Model for Radiological Protection. ICRP Publication 24: $1-3$.

12. Smith JR, Birchall A, Etherington G, Ishigure N, Bailey MR (2014) A revised model for the deposition and clearance of inhaled particles in human extra-thoracic airways. Radiat Prot Dosimetry 158: 135-147. [Crossref]

13. Leong BK, Coombs JK, Sabaitis CP, Rop DA, Aaron CS (1998) Quantitative morphometric analysis of pulmonary deposition of aerosol particles inhaled via intratracheal nebulization, intratracheal instillation or nose-only inhalation in rats. $J$ Appl Toxicol 18: 149-160. [Crossref]

14. Osier M, Oberdörster G (1997) Intratracheal inhalation vs intratracheal instillation: differences in particle effects. Fundam Appl Toxicol 40: 220-227. [Crossref]

15. Rao GV, Tinkle S, Weissman DN, Antonini JM, Kashon ML, et al. (2003) Efficacy of a technique for exposing the mouse lung to particles aspirated from the pharynx. $J$ Toxicol Environ Health A 66: 1441-1452. [Crossref]

16. Becker S, Soukup JM, Gilmour MI, Devlin RB (1996) Stimulation of human and rat alveolar macrophages by urban air particulates: effects on oxidant radical generation and cytokine production. Toxicol Appl Pharmacol 141: 637-648. [Crossref]

17. Dong W, Lewtas J, Luster MI (1996) Role of endotoxin in tumor necrosis factor alpha expression from alveolar macrophages treated with urban air particles. Exp Lung Res 22: 577-592. [Crossref]

18. Long CM, Suh HH, Kobzik L, Catalano PJ, Ning YY, et al. (2001) A pilot investigation of the relative toxicity of indoor and outdoor fine particles: in vitro effects of endotoxin and other particulate properties. Environ Health Perspect 109: 1019-1026. [Crossref]

19. Monn C, Becker S (1999) Cytotoxicity and induction of proinflammatory cytokines from human monocytes exposed to fine (PM2.5) and coarse particles (PM10-2.5) in outdoor and indoor air. Toxicol Appl Pharmacol 155: 245-252. [Crossref]
20. Menetrez MY, Foarde KK, Esch RK, Dean TR, Betancourt DA, et al. (2007) The Measurement of Ambient Bioaerosol Exposure. Aerosol SciTechnol 41: 884-893.

21. Van Winkle LS, Bein K, Anderson D, Pinkerton KE, Tablin F, et al. (2015) Biological Dose Response to PM2.5: Effect of Particle Extraction Method on Platelet and Lung Responses. Toxicol Sci 143: 349-359. [Crossref]

22. Wegesser TC, Last JA (2008) Lung response to coarse PM: bioassay in mice. Toxicol Appl Pharmacol 230: 159-166. [Crossref]

23. Moshell AN, Tarone RE, Newfield SA, Andrews AD, Robbins JH (1981) A simple and rapid method for evaluating the survival of xeroderma pigmentosum lymphoid lines after irradiation with ultraviolet light. In Vitro 17: 299-307. [Crossref]

24. Wegesser TC, Last JA (2009) Mouse lung inflammation after instillation of particulate matter collected from a working dairy barn. Toxicol Appl Pharmacol 236: 348-357. [Crossref]

25. Wang C, Quan LH, Guo Y, Liu CY, Liao YH (2007) Uptake and biodistribution of rizatriptan to blood and brain following different routes of administration in rats. Int $J$ Pharm 337: 155-160. [Crossref]

26. Lacher SE, Johnson C, Jessop F, Holian A, Migliaccio CT (2010) Murine pulmonary inflammation model: a comparative study of anesthesia and instillation methods. Inhal Toxicol 22: 77-83. [Crossref]

27. Osornio-Vargas AR, Bonner JC, Alfaro-Moreno E, Martínez L, García-Cuellar C, et al. (2003) Proinflammatory and cytotoxic effects of Mexico City air pollution particulate matter in vitro are dependent on particle size and composition. Environ Health Perspect 111: 1289-1293. [Crossref]

28. Schins RP, Lightbody JH, Borm PJ, Shi T, Donaldson K, et al. (2004) Inflammatory effects of coarse and fine particulate matter in relation to chemical and biological constituents. Toxicol Appl Pharmacol 195: 1-11. [Crossref]

29. Franzi LM, Bratt JM, Williams KM, Last JA (2011) Why is particulate matter produced by wildfires toxic to lung macrophages? Toxicol Appl Pharmacol 257: 182-188. [Crossref]

Copyright: (C2015 Linderholm AL. This is an open-access article distributed under the terms of the Creative Commons Attribution License, which permits unrestricted use, distribution, and reproduction in any medium, provided the original author and source are credited. 